\title{
Experiencias sobre el acercamiento del patrimonio malagueño a la ciudadanía
}

\section{Experiences on the approach of Malaga's heritage to citizenship}

\author{
Antonio Jesús Santana-Guzmán \\ Universidad de Málaga \\ asantana@uma.es \\ https://orcid.org/0000-0001-8132-192X
}

\begin{abstract}
Resumen
El presente trabajo expone una serie de procesos para la defensa del patrimonio arquitectónico y urbanístico de la ciudad de Málaga donde se ha participado de manera activa. Desde el rol del historiador del Arte como docente se pretende el acercamiento de la ciudadanía a los bienes culturales a través de un vínculo emocional que los convierta en imprescindibles. Lo que provocará que, en el caso de producirse actuaciones en cuyos procesos estos elementos se pusieran en peligro de desaparición o pudiesen sufrir algún tipo de mutilación, sean los propios habitantes los que procedan a defender cada una de estas causas. En este estudio se han considerado dos sectores, en primer lugar el alumnado universitario, con una formación específica; por otro lado el habitante, permanente o eventual, que se ubica en otros círculos pero que desarrolla su actividad en el territorio donde se localizan estos elementos arquitectónicos. La participación en el aula ha sido positiva y ha derivado en un aumento del interés y de la colaboración de los estudiantes en actos de defensa, mientras que en el trabajo con la ciudadanía ha resultado más complicada la implicación del residente, a pesar de que se han estudiado los perfiles de público y se han adaptado las herramientas de difusión y divulgación.
\end{abstract}

\section{Palabras clave}

Educación ciudadana, difusión, participación, patrimonio cultural, arquitectura, ciudad histórica.

Forma sugerida de citar: Santana-Guzmán, A.J. (2020). Experiencias sobre el acercamiento del patrimonio malagueño a la ciudadanía. Universitas, 33, pp. 103-124. 


\begin{abstract}
The present work exposes a series of processes for the defense of the architectural and urban heritage of the city of Malaga where it has been actively involved. From the role of the art historian as a teacher, the approach of citizenship to cultural goods is sought through an emotional bond that makes them essential. What will cause that, in the case of actions in whose processes these elements were put in danger of disappearance or could suffer some type of mutilation, it is the inhabitants themselves who proceed to defend each of these causes. In this study two sectors have been considered, first of all the university students, with specific training; On the other hand, the permanent or eventual inhabitant who is located in other circles but who develops his activity in the territory where these architectural elements are located. The participation in the classroom has been positive and has resulted in an increase in the interest and cooperation of students in acts of defense, while in the work with the citizenship the involvement of the resident has been more complicated, despite the fact that they have studied, they have studied the public profiles and the dissemination and dissemination tools have been adapted.
\end{abstract}

\title{
Keywords
}

Civic education, diffusion, social participation, cultural heritage, architecture, historic city.

\section{Introducción}

\section{La idiosincrasia de una ciudad como Málaga y su porqué}

La historia de Málaga (España) ha corrido en paralelo a la de su puerto, lugar natural de entrada a este enclave. Desde tiempos inmemoriales, esta ciudad ha sido reflejo de la realidad de cada una de sus épocas históricas y se ha ido transformando conforme la situación concreta de estos periodos. Los cambios más destacados han ido surgiendo a raíz de la pujanza económica que el comercio siempre le ha otorgado; modificaciones promovidas por estamentos bien posicionados y por personajes que se fueron estableciendo en ella atraídos por el reclamo de las posibilidades que esta tierra ha ofrecido y ofrece.

Asimismo, sus habitantes más modestos han participado en estas reformas, bien como parte de la mano de obra que las efectuaba, bien como me- 
ros espectadores, sin apenas opinión sobre las mismas. Esta posición distante de la ciudadanía, ha sido una constante también en lo referente a la conservación de su patrimonio y cultura. A día de hoy, y de manera generalizada, aún se mantiene esta actitud, aunque en ocasiones repuntan voces descontentas con ciertas intervenciones.

En Málaga se han asentado diversas culturas que han dejado amplios legados con interesantes ejemplos que conforman sus testimonios - fenicios, romanos, musulmanes, cristianos, etc.-. La mayoría de los bienes conservados actualmente son los que se han considerado y denominado "monumentales", siguiendo pautas que los vinculaban a conceptos sesgados, más relacionados con valoraciones históricas y artísticas en lugar de a la múltiple dimensión cultural.

Estos juicios están ya más que superados a nivel internacional. Según los criterios que actualmente se aplican sobre los bienes culturales no debe existir una prelación entre ellos, y si existiese, ésta no pude estar sometida a juicios de valor subjetivos sino al reconocimiento objetivo de su mayor carga significativa. Según el Consejo de Europa, "el Patrimonio es todo testimonio, de cualquier naturaleza, capaz de iluminar el pasado de la humanidad" (Campillos, 1998, p. 37). Con todo, en numerosas ocasiones se siguen utilizando principios desfasados en la selección de los bienes culturales que deben ser conservados y cómo, sin considerar la interpretación de sus contenidos referenciales imparcialmente.

Es evidente que cualquier transformación urbana conllevará la desaparición y creación de patrimonio. Centrándonos en el contexto territorial que nos ocupa - y preocupa - el Centro Histórico de Málaga está declarado, desde 2012, Bien de Interés Cultural (BIC), es decir, posee el rango más alto de salvaguardia existente en España; además su incoación tuvo lugar en 1985, por lo que, desde entonces y como medida cautelar, se debió determinar "la aplicación provisional del mismo régimen de protección previsto para los bienes declarados de interés cultural" (España, 1985: 20344). De la misma forma resulta obligatoria la redacción de un registro de los inmuebles característicos que lo componen, habiéndose aprobado en 1989 el Catálogo de Edificios Protegidos (Rein, 2013,p. 3) que jamás se ha actualizado, pues la única propuesta de revisión se convocó en marzo de 2018 y actualmente está paralizada a nivel judicial (Press, 2018).

El Gobierno central, tras la creación en 1981 de las Comunidades Autonómicas, ha ido cediendo competencias a los poderes regionales paulati- 
namente, entre ellas las relativas a Cultura. Por lo tanto, deberá ser la Junta de Andalucía quien vele y tutele, en última instancia, por los Bienes de Interés Cultural de Málaga, supervisando las intervenciones aprobadas por los ayuntamientos. Sin embargo, a lo largo de estas últimas décadas se han demolido elementos arquitectónicos singulares. En ocasiones, estas pérdidas han sido propiciadas por su abandono y desuso; en otras se ha procedido al derribo del interior, conservando tan sólo los muros exteriores, o parte, recurriendo al denominado "fachadismo", técnica rechazada por los expertos debido a la pérdida de patrimonio que provoca; también se han derruido edificios respondiendo a alineaciones delineadas en siglos anteriores, ya innecesarias; e incluso en alguna ocasión se ha propuesto el reemplazo de un elemento catalogado por una copia de nueva construcción. En ninguno de estos casos se ha considerado el soporte testimonial insustituible de estos bienes sobre los que se debe garantizar su perdurabilidad referencial.

Si el Centro Histórico de Málaga se corresponde con un pequeño sector y se trata de un espacio protegido, habrá que pensar entonces en la consideración que se tiene con la arquitectura que se emplaza fuera del mismo. Algunos elementos han llegado a formar parte de listados internacionalmente reconocidos, aunque sin amparo efectivo, por lo que han desaparecido a pesar de sus destacados valores patrimoniales.

\section{El lento y selectivo despertar de la ciudadanía}

Si hay un hecho destacado en la cultura malagueña en la que su ciudadanía se implicó, ese fue el de "La Aduana para Málaga" (Figura 1). Esta acción surgió como protesta al cierre de las dos secciones que componían el Museo de Málaga. En 1996 la de Arqueología, instalada en la Alcazaba, y al año siguiente, la de Bellas Artes, ubicada en el conocido como Palacio de Buenavista, tras seleccionarse como futuro Museo Picasso Málaga. De manera "provisional" los fondos de esta última se trasladaron al ático del Palacio de la Aduana, un imponente edificio neoclásico que acogía diversas funciones administrativas.

Sería en ese mismo año cuando un amplio número de colectivos conformasen la denominada "Comisión Ciudadana La Aduana para Málaga", que solicitaba que dicho edificio se convirtiese en sede definitiva del Museo de Málaga. El 12 de diciembre de 1997 se convocó una manifestación a la que 
acudieron 5000 personas, sin duda una de las mayores concentraciones conocidas en el ámbito de la cultura malagueña (MemorAnda, 2016); y a ésta le siguieron tres más en 1998 y 2001, así como varios encierros. En septiembre de 2005 fue cedido por parte del Gobierno central (Martínez, 2013, pp. 39-40) y en diciembre de 2016 se inauguró ya como Museo de Málaga.

Sin lugar a dudas estas acciones sucedieron porque el residente se sintió plenamente identificado con sendas colecciones expositivas, pues las consideraba su herencia y por lo tanto algo propio, tal y como lo es. Desafortunadamente, este acontecimiento, el más sobresaliente en el que la ciudadanía malagueña ha mostrado su interés y preocupación por su patrimonio, no ha vuelto a producirse ni a tal escala ni con tanta intensidad.

\section{Figura 1}

\section{Logotipo y lema de las manifestaciones a favor de la Aduana}

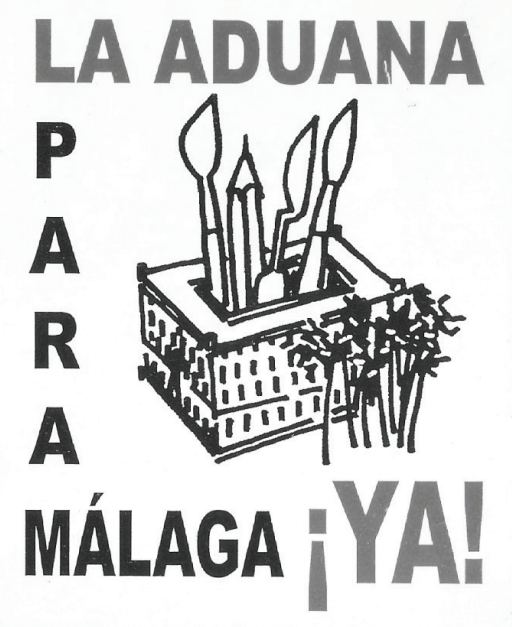

Archivo A. Santana.

Dicha desidia ha repercutido en la desaparición patrimonial. Se destacan aquí dos casos de nuestro patrimonio industrial: el del Silo del puerto y el de la fábrica de Citesa. El Silo (1942-1949), un interesantísimo e imponente almacén, fue demolido en 2006 para convertir el antiguo muelle donde se erigía en un amplio paseo dotado con espacios verdes y en el que se levantaron 
nuevas construcciones; en ningún momento las administraciones competentes aceptaron las propuestas de integración y adaptación a otros usos, entre ellas hosteleras y culturales, a pesar de que actualmente el espacio las acoge. Posteriormente, en 2009, desapareció el antiguo edificio de la Compañía Internacional de Telecomunicaciones y Electrónica, Citesa (1962-1963), un inmueble rodeado por un denso tejido residencial, que podría haber sido reutilizado como equipamiento, con infinidad de posibilidades debido a su interior diáfano, tal y como se planteó; además se encontraba incluido en el Registro de la Fundación Docomomo (Barrera \& Santana, 2014).

Como se ha indicado, en ninguno de estos dos casos se creó un movimiento ciudadano para la defensa de estas interesantes piezas arquitectónicas, si bien, el proyecto de Citesa, en cuyo solar se está actualmente construyendo otro complejo residencial, ha despertado las molestias de los vecinos en relación a los espacios verdes y servicios públicos planteados.

Cabe también nombrar el caso del Hoyo de Esparteros, sector contiguo a la avenida principal del Centro Histórico, la Alameda. Durante varias décadas parte de este caserío estuvo completamente abandonado y varios de sus inmuebles históricos fueron demolidos a pesar de tener pinturas murales o estar proyectados por los arquitectos decimonónicos más destacados de Málaga. Al menos, desde 2004, se planteó la construcción de un hotel, para ello resultaba necesario unificar parcelas, anexionar una vía pública y demoler un edificio que contaba con protección arquitectónica; la ficha de éste se eliminó en 2008, por parte de la administración local, del Catálogo de Edificios Protegidos del Plan Especial de Protección y Reforma Interior (PEPRI) (Málaga, 2008). Ese mismo año, la edificabilidad del nuevo inmueble se multiplicó considerablemente, a la vez que aparecía firmado por un arquitecto de fama internacional. En 2012, el Gobierno regional aprobó, de manera definitiva, las modificaciones necesarias para permitir esta operación inmobiliaria.

La pieza descatalogada fue calificada por las administraciones y por parte de los periódicos locales como una vieja pensión en ruinas (Ruiz, 2019), La Mundial, nombre que adquirió durante su última función. Si bien, en origen fue la residencia urbana de los Heredia Loring, condes de Benahavís, y fue diseñada (1892-1894) por Eduardo Strachan Viana-Cárdenas, autor de la vía más icónica de la ciudad, la del Marqués de Larios (1887-1891). Así mismo conservaba un gran número de elementos originales, a pesar de su estado de abandono.

Para la salvaguarda de este bien arquitectónico, a finales de 2010, se conformó un grupo activo de expertos y residentes, que se denominó Plataforma 
Ciudadana en Defensa del Hoyo de Esparteros. Pero sus interesantes acciones no evitaron su demolición, aunque hubo una breve paralización judicial, y en marzo de 2019 fue derribado (Sau, 2019-03-11; 2019-03-21). Del mismo tan sólo se salvaron los herrajes de sus balcones y pequeñas muestras de su decoración interior, todo para integrarlo en una copia que, sin sentido alguno, se realizará en el entorno cercano. Asimismo, durante su destrucción se descubrió que sus forjados estaban realizados con metal, siendo, junto a los inmuebles de calle Larios, uno de los primeros ejemplos documentados en esta ciudad.

Una lucha con un final más positivo fue la salvaguarda del Convento de San Agustín (siglos XVI-XX), donde el Gobierno central ha propuesto la ubicación de la Biblioteca Pública del Estado. En 2008 se redactó un proyecto, modificado posteriormente, que era bastante desconsiderado con el cenobio ya que lo demolía en parte y desvirtuaba sus elementos originales. Ante tal situación, tanto la ciudadanía como la Asociación de Antiguos Alumnos, ya que fue colegio de los agustinos, consiguieron presionar a la administración, logrando que en 2018 el Ministerio de Cultura paralizara la intervención (Vázquez, 2018). Además, permitió el análisis in situ del convento a través de un estudio arqueológico parietal que está haciendo aflorar datos hasta ahora desconocidos y que dan paso a nuevas interpretaciones sobre la configuración original del conjunto.

\section{Material y métodos}

\section{La dificultad de acercarse a la ciudadanía}

Este trabajo se ha centrado en intervenciones en las que, en mayor o menor medida, se ha participado de manera activa, desde el rol del historiador del Arte. Como el marco temporal que se abarca es tan amplio, desde la década de los años 90 del siglo XX hasta hoy, el material, las herramientas, las técnicas y los instrumentos utilizados en cada una de ellas ha ido variado considerablemente, si bien las estrategias son las mismas: en primer lugar, dar a conocer el patrimonio local y la situación en la que se encuentra, siempre haciendo uso de la difusión en los diversos estadios; en segundo, conseguir que el individuo sea consciente de que el patrimonio y la cultura generada por su sociedad -pasada y presente- le pertenecen. Finalmente, los reconocerá y se identificará con ellos, produciéndose una apropiación de los 
mismos en sentido intelectual y emocional. Será entonces cuando se sentirá capaz de defenderlos y de dar voz a la necesidad de salvaguardarlos.

\section{Las herramientas de difusión adaptadas al momento y a las necesidades}

Para acercarse a la ciudadanía se debe hacer uso de los medios que esta utiliza de manera cotidiana. Así, una de las formas más acertadas para dar a conocer lo que ocurre con el patrimonio de una ciudad es la prensa de ámbito local. En el contexto de la defensa del Silo del puerto y del edificio de Citesa, en 2006 y 2009, respectivamente, se planteó la publicación de textos breves pero concisos en los diarios malagueños, ya que alcanzarían un amplio espectro de lectores aportándoles información de manera más cercana.

Para el primero de los casos, se redactaron varios artículos por parte de miembros del Departamento de Historia del Arte de la Universidad de Málaga (UMA), bien de manera colectiva, bien individual (Camacho et al., 2006; Santana, 2006). La intención fue la de hacer comprender a los ciudadanos que un bien arquitectónico ya existente podía readaptarse e insertarse perfectamente en la nueva propuesta urbana del muelle portuario, convirtiéndose además en su pieza principal (Figura 2).

\section{Figura 2}

\section{Demolición del Silo del puerto. 2006-05-24}

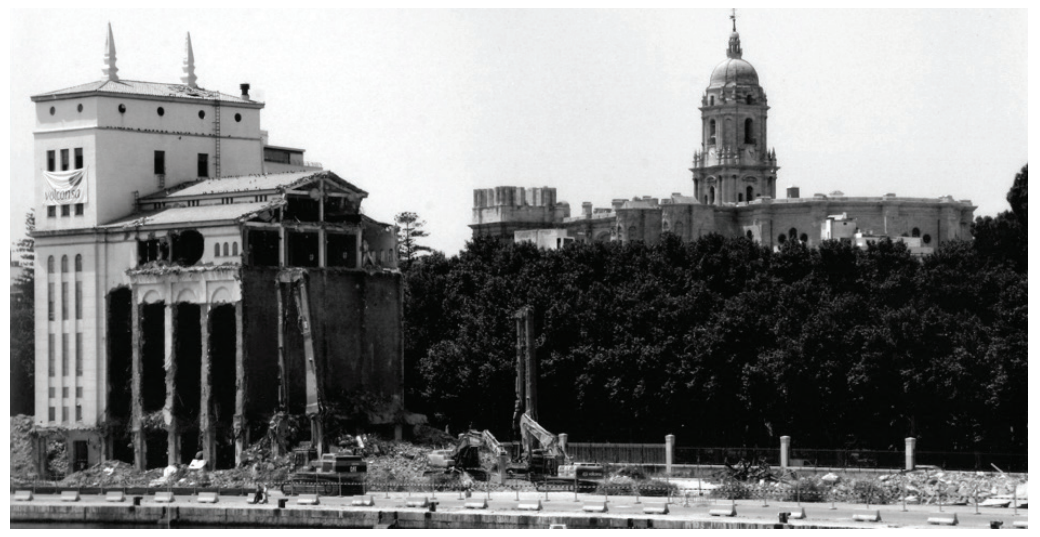

Fotografía: A. Santana. 
En el segundo se aunaron dos disciplinas, la Arquitectura y la Historia del Arte, firmándose el correspondiente artículo por parte de dos profesionales formados en cada una de ellas. En esta ocasión, no sólo se pretendía exponer que las características de la nave industrial de Citesa permitían acoger diversas funciones de equipamiento para una zona con una elevada densidad de población, sino también indicar que sus valores patrimoniales habían logrado que se insertase en el registro de edificios de la Fundación Docomomo, especializada en la documentación y conservación de la arquitectura y el urbanismo del movimiento moderno, y cuya parte dedicada a la provincia de Málaga había sido redactada por el arquitecto Sebastián del Pino Cabello. En esta ocasión existía una importante entidad que defendía su mantenimiento, como es el caso del Colegio Oficial de Arquitectos de Málaga. Asimismo, los antiguos trabajadores de la fábrica apoyaron esta decisión reproduciendo el texto del artículo en su blog antes que la prensa (Del Pino \& Santana, 2009-09-13; 2009-09-15) (Figura 3).

\section{Figura 3}

\section{Fábrica de Citesa antes de su demolición}

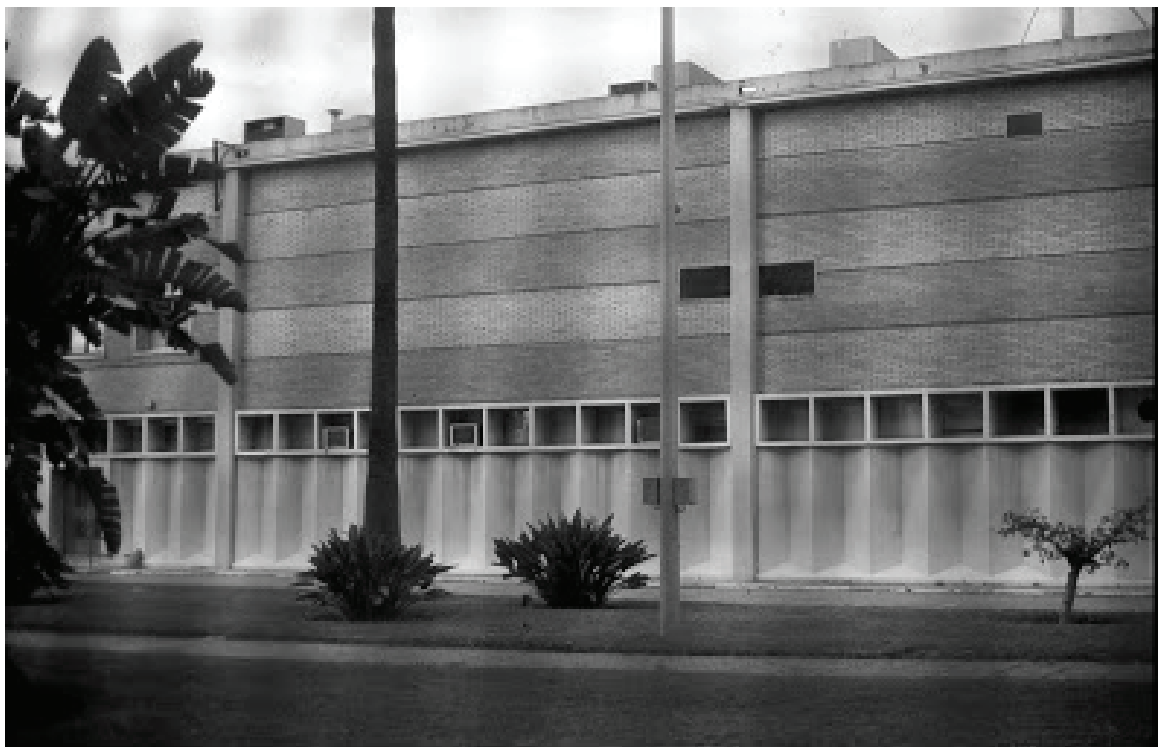

Ca. 2009 (Del Pino \& Santana. 2009-09-13). 
Desafortunadamente, en sendos procesos, no se lograron detener las fatídicas demoliciones.

Con el paso del tiempo, internet se ha convertido en una herramienta esencial para difundir cualquier tipo de información. La aparición del texto sobre Citesa en la red fue la primera aportación en un medio completamente digital, allá por 2009. Pero para hablar de éxito a la hora de movilizar a la ciudadanía malagueña a través de las nuevas tecnologías, tenemos que remitirnos a casos posteriores, concretamente al del Hoyo de Esparteros y al del Convento de San Agustín.

La experiencia de La Mundial, ha sido sin duda, la que ha marcado un punto de inflexión en el tema de la salvaguarda del patrimonio en Málaga y además es una de las que más esfuerzo ha generado, requiriendo una mayor implicación. Se comenzó en 2010 con una reunión en la que se convocó a participantes formados en diversas materias - Arquitectura, Geografía, Historia del Arte, Industriales, etc.- - dando así lugar a un importante grupo multidisciplinar. En dicha puesta en común se expuso la situación desde varias perspectivas y se decidió que los tres pilares a tener en cuenta serían: la investigación, la difusión y la publicación de resultados.

El punto de partida fue la búsqueda de información abarcando diversos campos y enfocándola a varias finalidades concretas. En relación al urbanismo se hizo un rastreo de la cartografía histórica del lugar para concretar cuándo se configuró el entorno; para conocer la arquitectura del edificio en peligro y su historia se comenzó con la consulta de bibliografía ya publicada que, aunque no era mucha, sí facilitó datos esenciales que llevaron a documentos originales en los principales archivos - Municipal e Histórico Provincial-; también se hizo un barrido de las normativas de protección a diversos niveles - nacional, regional y local - para ello se consultaron la Ley del Patrimonio Histórico Español (LPHE), la Ley del Patrimonio Histórico de Andalucía (LPHA), el PEPRI del Centro Histórico de Málaga y el Catálogo de Edificios Protegidos.

La difusión pública de los datos recopilados resultaba esencial, haciéndose uso de internet para una mayor divulgación. Así, la primera actuación fue la creación de un manifiesto que se subió a diversas redes sociales (Figura 4). En él se solicitaba la paralización del proyecto, la restauración y puesta en valor de la arquitectura y la conservación del trazado urbano; igualmente se exigían consultas ciudadanas para futuras ordenaciones urbanas. Este documento recabó 500 firmas de particulares y colectivos de toda Espa- 
ña, lo que abrió una nueva opción de trabajo: la realización del denominado I Encuentro en Defensa de la Ciudad y el Patrimonio (EDCP) en Málaga en octubre de 2011. A él acudieron diversas asociaciones y plataformas de otras provincias para dar visibilidad a sus problemas (Figura 5).

\section{Figura 4 \\ Cartel del manifiesto en defensa del Hoyo de Esparteros y La Mundial}

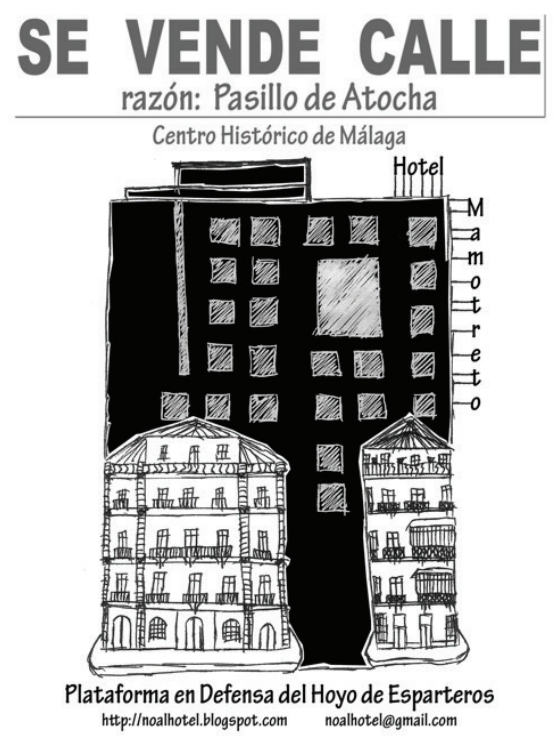

Archivo A. Santana.

Sin lugar a dudas, el uso de internet fue esencial en este movimiento, derivando en la creación de nuevos blogs en defensa del patrimonio malagueño y en la creación de peticiones a través de Change.org, llegando a alcanzarse más de 6000 firmas (Torre Vigía, 2013) Pero, como ya se ha indicado con anterioridad, resultaba primordial dar a conocer los valores urbanísticos y arquitectónicos del Hoyo de Esparteros a un público más próximo a su entorno. Para ello se eligió un importante punto de encuentro ciudadano, próximo a este enclave, el Mercado de Atarazanas. Allí se expuso y se explicó a los vecinos y viandantes la situación. 


\section{Figura 5 \\ Cartel del EDCP. Málaga. 2011}

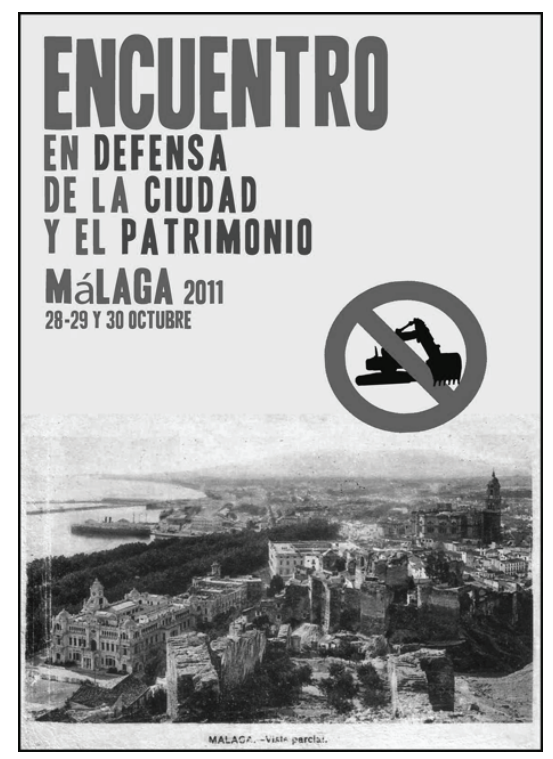

Archivo A. Santana.

En cambio, para hacer una difusión más académica se decidió publicar un concienzudo artículo en una importante revista cultural y científica local, impresa en papel, donde además se propuso su rehabilitación como centro documental relacionándolo con la importante biblioteca que tuvo su primer propietario (Santana, 2009 [2011]). Estos valores también se dieron a conocer en conferencias y ciclos especializados sobre patrimonio (Santana, 2018).

Con esta metodología quedaba cubierto un mayor espectro que en casos anteriores. Este patrimonio se acercó de manera más directa tanto a especialistas como a gente que no lo era, y a través de internet se le dio difusión nacional al caso, que acabó saliendo en prensa y televisión. Tanto es así que la reconocida asociación Hispania Nostra incluyó el Palacete Benahavís La Mundial - en su Lista Roja del Patrimonio, junto a otros elementos en "riesgo de desaparición, destrucción o alteración esencial de sus valores". A pesar de todos los esfuerzos, el inmueble fue demolido y entró a formar parte de la denominada Lista Negra (Hispania, 2019). 
El último episodio destacado dentro del movimiento a favor de nuestro patrimonio ha sido la salvaguarda del Convento de San Agustín. En este caso, la propuesta para convertir este antiguo cenobio, ubicado a escasos metros de la Catedral, en biblioteca estatal ponía en peligro y desvirtuaba gran parte de su conjunto debido a un proyecto bastante agresivo. Para conseguir conservarlo con un mayor número de apoyos ciudadanos, se realizaron varios llamamientos en el portal Change.org entre 2015 y 2018, contando el último de ellos con más de 1500 firmas (Edifeicios, 2018) (Figura 6). Ese mismo año se paralizó la intervención, surgiendo así una nueva fase de estudio que aún está en proceso (Santana, 2020/2021).

\section{Figura 6}

\section{Imagen utilizada en Change.org con el hashtag \#SalvemosSanAgustin (Edifeicios, 2018)}

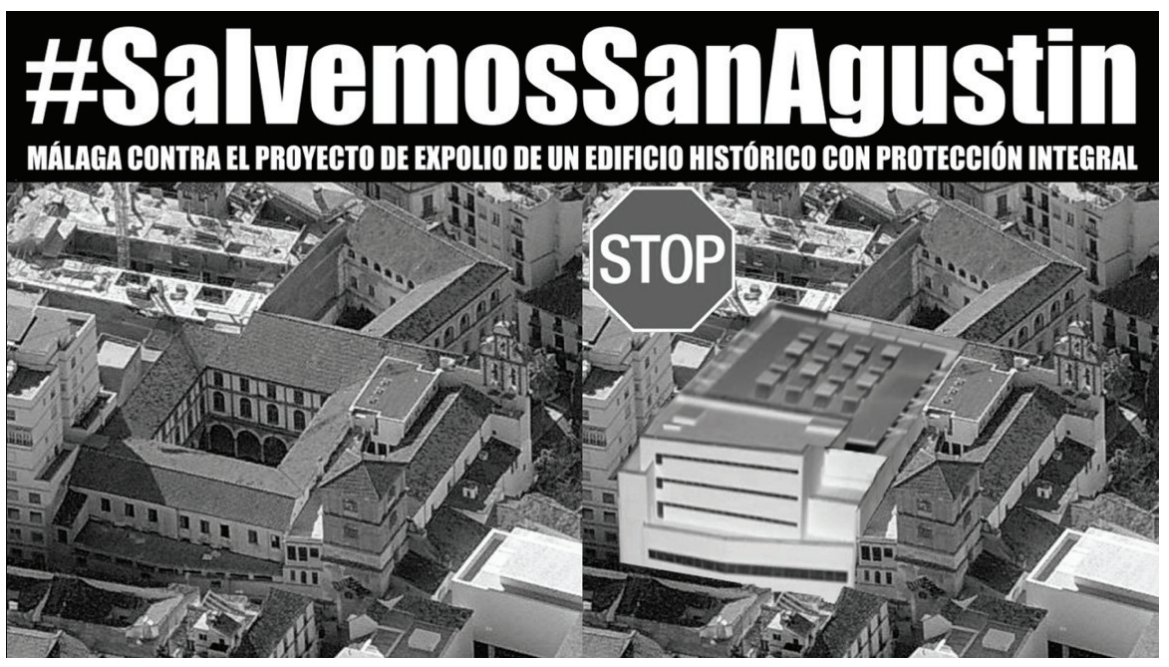

Tanto en el tema del Hoyo de Esparteros como en el del Convento de San Agustín, el uso de las redes sociales conllevó la creación de diversas etiquetas o hashtags. En primer lugar \#SalvemosLaMundial, que posteriormente fue sustituida por \#RIPLaMundial y por \#RecuerdaLaMundial; aún hoy estas se usan en relación a situaciones de peligro del patrimonio malagueño; y en segundo lugar \#SalvemosSanAgustin. 
Como se ha expuesto, los métodos utilizados en cada uno de estos procesos han sido variados y se han desarrollado en relación al momento en el que se han realizado las defensas, dependiendo de las herramientas existentes en cada tiempo. Pero en todos los casos han sido esenciales dos pasos: la investigación y la difusión local.

\section{El aula como atril}

Sin lugar a dudas, la clase donde se imparte Historia del Arte es el lugar idóneo para crear conciencia sobre el patrimonio. Posiblemente ésta será la primera vez en la que el alumnado se suscriba a un acto en defensa de los bienes culturales y por tanto el momento inicial en la materia. Esta actitud será una herencia legada por parte de los profesores a los futuros investigadores y, a la vez, calará, en mayor o menor medida, en el entorno más cercano de cada uno de estos individuos.

En relación con este punto este trabajo recopila una serie de actividades realizadas en los últimos años en la docencia impartida por el que suscribe como profesor e investigador del Departamento de Historia del Arte de la UMA.

Algunas de ellas se han enmarcado en el Proyecto de Innovación Educativa (PIE) 17-068 dirigido por Francisco José Rodríguez Marín, donde se ha pretendido la interactuación del alumnado y profesorado universitario de Historia del Arte y Turismo, de Educación Primaria y de Secundaria. Dichas tareas han propuesto el acercamiento de los estudiantes de instituto al patrimonio local a través de la visión de los alumnos universitarios, con los que guardan una pequeña diferencia de años y que en breve se convertirán en historiadores del Arte. Para ello, en el curso 2017/2018 se propuso a los inscritos en la asignatura Historia del urbanismo investigar, mediante bibliografía ya existente y trabajo de campo, algunas iglesias del Centro Histórico de Málaga y realizar una ruta in situ adaptada al alumnado de secundaria. En el sucesivo año académico 2018/2019, se planteó una participación completamente diversa, con la misma metodología, pero con un resultado distinto: planificar una exposición, que podría ser instalada tanto en una facultad como en un instituto, sobre diversos tipos de bienes a través de paneles con imágenes en los que se insertan códigos QR que enlazarían con una web donde se alojarían los datos específicos de cada elemento. Este diseño obliga al espectador a interactuar a través de un dispositivo electrónico, por ejemplo, un teléfono móvil, soporte que está presente en el quehacer diario y principalmente en el de cualquier adolescente y joven. El citado proyecto 
se ha desarrollado en las asignaturas de Patrimonio etnográfico y arte popular y en la de Arte de las culturas no occidentales.

Del mismo modo se ha trabajado en la Red de Excelencia Trans-UMA, dirigida por Nuria Rodríguez Ortega, que desarrolla un ecosistema de aprendizaje orientado a facilitar una formación transdisciplinar entendida como integración de saberes heterogéneos, en la que se combina acción y pensamiento crítico. Se ha llevado a cabo en el curso 2018/2019, junto a los docentes Julia García González, María Marcos Cobaleda e Iván de la Torre Amerighi. Esta actividad se denomina "Patrimonio herido", resultando esencial la formación del Grado de Turismo y el Grado de Historia del Arte y las programaciones docentes de las asignaturas implicadas, siendo éstas Gestión del patrimonio cultural e Historia y conceptos fundamentales del patrimonio cultural, respectivamente. El proceso se desarrolló en dos fases. En la primera, los estudiantes de Turismo seleccionaron, con completa libertad, un elemento patrimonial, de la capital, que considerasen que estaba en peligro por cualquier razón. Sobre el mismo presentaron un pequeño resumen explicando su elección, acompañando por un selfie delante del monumento. En la segunda, el alumnado de Historia del Arte, teniendo como base ese texto, configuró una ficha más elaborada en la que se recogía un numero más amplio de datos: el análisis de la situación; el grado de protección; dos propuestas, de primeros auxilios y de intervención; bibliografía existente; y un dosier con imágenes históricas localizadas a través de diversos archivos, así como actuales, realizadas por ellos mismos. En ambos casos se vieron obligados a visitar el bien en cuestión y a conocerlo in situ. Esta tarea concluyó con una puesta en común entre ambas clases, resultando muy positiva pues se exponen casos prácticos donde los estudiantes pueden conocer de primera mano problemas que quizás no hubiesen visto en el desarrollo de la teoría, presentando además posibles soluciones a los mismos; algo que agradecieron los propios alumnos. La actividad se ha repetido en 2019/2020, pero adaptada a la inusual situación del COVID-19.

\section{Análisis y resultados}

La finalidad de las defensas o propuestas de trabajo recopiladas en este estudio, no es sólo la conservación del elemento patrimonial, sino conseguir la implicación del individuo que habita el territorio - bien de manera per- 
manente, bien de manera eventual- donde se emplazan los elementos arquitectónicos expuestos. Sin lugar a dudas ese compromiso será fundamental, ya que, si no se genera una identificación entre el ciudadano y los bienes culturales, no tendrá sentido la conservación de los mismos.

Desde el perfil profesional que aquí se expone: el historiador del Arte como docente, es muy importante considera al alumnado, ya que, se entiende $-\mathrm{o}$ al menos se espera - que será el sector que más se sienta unido al patrimonio por su decisión de cursar estudios relacionados con el mismo. En cambio, resulta mucho más complicado involucrar a la ciudadanía, ya que en la mayoría de ocasiones no se considera tan vinculada emocionalmente con el elemento en peligro. Por lo tanto, será necesaria una mayor implicación, desde diferentes disciplinas, y un esfuerzo mucho más grande para mostrar dicha proximidad.

A nivel docente, la implicación directa de los estudiantes con el patrimonio ha sido un éxito, pues se ha conseguido que analicen las causas y consecuencias que provocan el deterioro y la pérdida de patrimonio además de que propongan soluciones, lo que ha generado un incipiente interés que ha desembocado en debates y consultas incluso sobre casos que no se habían planteado ni en el aula ni en los trabajos ya referidos.

Por otro lado, y aunque resulta más arduo crear nexos de unión entre la ciudadanía y los bienes culturales, si hay que considerar que el caso del Hoyo de Esparteros, a pesar de su nefasto final, su proceso se ha convertido en un punto de inflexión dentro de los casos de defensa del patrimonio, debido principalmente al apoyo que se creó para la salvaguarda del Palacete Benahavís y el empeño de las administraciones públicas en su destrucción y sustitución por una copia a la que, considerándola como "réplica" le atribuyen el mismo valor, indicándose además que así se conservará el edificio (El Observador, 2011).

\section{Discusión y conclusiones}

Es necesario indicar que resulta esencial la actitud de la administración pública respecto a la gestión urbana. En Málaga, el desarrollo turístico es tan fuerte que se ha creado una serie de intereses que en muchas ocasiones perjudica al patrimonio inmueble, ya que éste se convierte en un recurso estratégico "para el desarrollo malagueño, aun dando por sentado que este de- 
sarrollo, a veces, no tiene en cuenta de forma homogénea, coherente ni unitaria los valores de tales recursos" (Silva \& Fernández, 2017, p. 82).

Generalmente estos poderes oficiales se han limitado única y exclusivamente a considerar las protecciones que se recogen en el Catálogo de Edificios Protegidos, del cual hay que recordar que lleva sin actualizar desde su creación en 1989. Incluso en alguna ocasión, tal y como se ha indicado, se ha llegado a eliminar alguna de sus fichas para permitir la destrucción de un edificio, en otros casos incluso se han demolido completa o parcialmente arquitecturas aún inscritas en él, lo que genera un proceso artificioso de reinvención patrimonial. Aunque también es necesario destacar aquí que en algunos casos existe un interés desde la propia administración por proteger piezas que no estaban inscritas en ningún listado oficial y que por lo tanto carecían de protección. Tal es el caso del edificio residencial Melilla 31 (1967-1971) que se ha propuesto para su inclusión en el Catálogo General del Patrimonio Histórico Andaluz para evitar graves modificaciones en su interesante portal, siendo obra de Antonio Lamela (Vázquez, 2020).

Por otro lado, cabe resaltar los procesos acaecidos en la ciudad en los que se habla de recuperación de inmuebles históricos y de la regeneración de un tejido - no siempre - abandonado (Ertan \& Egercioglu, 2016, p. 604). Una de las evoluciones más destacadas es la que ha sufrido este territorio al pasar de ser un destino de sol y playa a un referente cultural. Desde finales del siglo XX se rehabilitaron y transformaron inmuebles para su conversión en espacios expositivos, creando una impresionante red de museos que ha colocado a Málaga en el mapa internacional a este respecto. En relación a este proceso debemos destacar la fallida candidatura a Capital Europea de la Cultura 2016 (Paü, 2017, p. 250). Esta situación derivó en planes y procesos que en su mayoría supeditan el uso del Centro Histórico al turista (Barrera \& Hernández, 2017, p. 157), convirtiéndolo en ocasiones en un espacio poco atractivo para el habitante. Asimismo, estas intervenciones pueden desarrollarse en paralelo a procesos de gentrificación, de pérdida de autenticidad y poseen una visión demasiado elitista sobre los bienes culturales.

La idiosincrasia de esta localidad y su constante transformación a lo largo de los siglos, ha influido en la actitud del malagueño sobre su patrimonio. Gran parte de los ciudadanos entiende los bienes como un producto que se oferta y que por lo tanto según la demanda puede transformarse o sustituirse sin problema alguno, siempre que sea en beneficio del turismo entendido - y ofrecido - como el único gran motor económico de la ciudad (Santana, 
2020). Es importante recordar que la conservación del patrimonio no debe conllevar aparejado un concepto estático del mismo como elemento aislado, sino que debe entenderse como un ente vivo y dinamizador del territorio (Unesco, 2013, p. 19).

Para cerrar cabría indicar que no existe una fórmula perfecta para conseguir que la ciudadanía se sienta identificada con el patrimonio, independientemente de que la vía de asignación de los valores patrimoniales de los bienes se realice de arriba abajo o de abajo arriba, es decir, que parta de las administraciones públicas o bien desde el habitante. Con todo, resulta imprescindible que el individuo se vincule con el bien en concreto y no con los intereses que se han plasmado en él, pues esto podría suponer una asignación de valores cambiantes y por lo tanto perderlos a nivel cultural (Silva \& Fernández, 2017, pp. 82,93). Es necesario que lo sienta el patrimonio como propio y para ello es esencial la creación de un vínculo emocional que haga que éste se convierta en imprescindible.

Este es un asunto educacional, por lo que será fundamental conocer y estudiar el perfil de los individuos a los que queremos dirigir la información y seleccionar las herramientas necesarias en cada caso. Aunque enviar el mensaje al ciudadano no siempre implica una respuesta positiva por parte del mismo, por lo que tocará lidiar, en mayor o menor grado, en la creación de una conciencia sobre los bienes culturales. Ésta es la única manera de generar caminos y fórmulas hacia la gobernanza participativa. Se debe conseguir que la colectividad se vea reconocida en el legado histórico que existe en su entorno.

Asimismo, el resultado negativo en un proceso de defensa, aunque no deseado por la pérdida de elementos destacados de nuestra herencia cultural, no debe influir de manera perjudicial en nuestra labor y en nuestro esfuerzo. Esta situación debe servir para reforzar la búsqueda de nuevas técnicas, instrumentos y estrategias.

\section{Bibliografía}

Barrera-Fernández, D., \& Hernández-Encampa, M. (2017). Spatial analysis of tourist activities and services in the historic city. The cases of Malaga and Plymouth. European Journal of Geography, 7(5), 139-160. https://bit. ly/32fAzAS 
Barrera-Fernández, D., \& Santana-Guzmán, A.J. (2014). Citesa. Una joya perdida del patrimonio industrial malagueño. III Jornadas Andaluzas de Patrimonio Industrial y de la Obra Pública. https://bit.ly/3iYJgGa

Camacho-Martínez, R., Asenjo-Rubio, E., Rodríguez-Marín, F., Sánchez-Luque, M., \& Santana- Guzmán, A. (2006-03-01). El silo de Málaga. Diario Sur, 20.

Campillo-Garrigós, R. (1998), La gestión y el gestor del Patrimonio Cultural. Editorial KR.

Del Pino-Cabello, S., \& Santana-Guzmán, A.J. (2009-09-13). Citesa: de edificio catalogado a equipamiento cultural, social y deportivo para el barrio de Martiricos. Citesa. Compañía Internacional de Telecomunicaciones y Electrónica $S . A$. https://bit.ly/34gfrwM

Del Pino-Cabello, S., \& Santana-Guzmán, A. J. (2009-09-15). Un edificio singular. Diario Sur, 17.

Edifeicios Málaga (2018-09-17). Salvemos San Agustín (Málaga). Change.org. https://bit.ly/2Q9kTt9

El Observador (2011-01-04). El arquitecto Rafael Moneo hará una réplica de la pensión 'La Mundial' en su proyecto de hotel y de oficinas para Hoyo de Esparteros de Málaga. El Observador. https://bit.ly/3aIIgU0

Ertan, T., \& Egercioglu, Y. (2016). Historic City Center Urban Regeneration: Case of Malaga and Kemeralti, Izmir. Procedia Social and Behavioral Sciences, 223, 601-607. https://bit.ly/3gf061N

España (1985-06-25). Ley del Patrimonio Histórico Español. Tít. 1. Art. 11.1. Boletín Oficial del Estado (BOE, 1985-06-29). 155, 20344. https://bit. ly/3aFyEJm

Hispania Nostra (2019-02-14). Palacete de los Condes de Benahavís-La Mundial. Lista Roja del Patrimonio. https://bit.ly/311SB1X

Málaga (2008-08-07). Acuerdo de la Junta de Gobierno Local de fecha 16 de mayo de 2008, de desestimación de alegaciones y apertura de nuevo trámite de información pública del expediente de modificación de elementos del PEPRI Centro en calle Hoyo de Esparteros. Edicto 11509/08. Boletín Oficial de la Provincia de Málaga (BOAM, 2008-10-03). 191, 38. https:// bit.ly/313zsg8

Martínez-Madrid, R. (2013). La Asociación Amigos del Museo de Málaga, Bellas Artes y Arqueológico. Boletín de la Sociedad de Amigos de la Cultura de Vélez-Málaga. 12, 39-42. https://bit.ly/31duOnN

MemorAnda (2016-12-16). La Aduana para Málaga 1997: antecedente del Museo de Málaga. Archivo Canal Sur. https://bit.ly/32asEok 
Paül i Agustí, D. (2017). La Capital Europea de la Cultura de España 2016. Análisis comparative de Donostia-San Sebastián, ciudad designada, y las candidaturas de Málaga y Zaragoza [The Spanish European Capital of Culture 2016. A comparison between Donostia-San Sebastián, designated city, and the unsuccessful applications of Málaga and Zaragoza]. Cuadernos Geográficos, 56(1), 242-264. https://bit.ly/2YhAZW5

Press (2018-04-24). Colegio de Arquitectos recurre contra la licitación para revisión del catálogo de edificios protegidos del Pepri centro. Europa Press. https://bit.ly/3aNUr1F

Rein-Lorenzale, M. (2013-12). Informe sobre intervenciones urbanísticas y transformaciones físicas en el ámbito del PEPRI Centro, 3. En Ayuntamiento de Málaga, Servicio de Programas. https://bit.ly/34gxGSN

Ruiz, I. (2019/03/31). La piqueta tira la vieja pensión de Málaga donde se levantará un hotel de Moneo. ABC Andalucía. https://bit.ly/3heB3gL

Santana-Guzmán, A.J. (2006-04-21). El puerto de Málaga. Diario Sur, 22.

Santana-Guzmán, A.J. (2009 [2011]). Patrimonio y Ciudad: 'La Mundial', último testigo del pasado burgués del Hoyo de Esparteros, propuesta como futura sede del Centro Documental Heredia Loring-Condes de Benahavís. Isla de Arriarán. 34, 7-43. https://bit.ly/31bbF5Q

Santana-Guzmán, A.J. (2018-11-18). El Palacete Benahavís, el edificio de Strachan que se ha convertido en símbolo de la Defensa del Patrimonio Arquitectónico y Urbanístico de Málaga. Málaga: un escenario único 8 (Homenaje a la Ilma. Sra. Sa Rosario Camacho Martínez, Málaga).

Santana-Guzmán, A.J. (2020), Actuaciones sobre el patrimonio arquitectónico de Málaga en su conversión en espacios expositivos [Interventions on the architectural heritage of Malaga in its conversion into exhibition spaces]. I Simposio anual de Patrimonio Natural y Cultural ICOMOS España. Valencia: Univesitat Politècnica [En prensa].

Santana-Guzmán, A. J. (2020/2021). El movimiento de la sociedad malagueña para la conservación del antiguo convento de San Agustín ante el proyecto de transformación en Biblioteca Pública del Estado. En B. Calderón Roca (Coord.), Educación cultural y ciudadanía en el siglo XXI: Cómo comunicarnos. Tirant Lo Blanch [En prensa].

Sau, J.A. (2019-03-11). Un juzgado paraliza el derribo de La Mundial de forma cautelar. La Opinión de Málaga. https://bit.ly/2Qav0xL

Sau, J.A. (2019-03-21). El juez autoriza la demolición de La Mundial. La Opinión de Málaga. https://bit.ly/3gdWMEm 
Silva-Pérez, R., \& Fernández-Salinas, V. (2017). El patrimonio en la reinvención de Málaga. Agentes, instrumentos y estrategias [Heritage in the reinvention of Malaga. Instruments, agents and strategies]. Investigaciones Geográficas, 67, 81-100. https://doi.org/10.14198/INGEO2017.67.05

Torre Vigía (2013-03-01). Salvar la Mundial. Change.org. https://bit.ly/2Fxf1aX

UNESCO (Ed.) (2013). Managing Cultural World Heritage Resource Manual. Paris: ICOMOS, 19. https://bit.ly/3aHNXRT

Vázquez, A. (2018-10-04). El Ministerio de Cultura frena el proyecto de la Biblioteca en San Agustín. La Opinión de Málaga. https://bit.ly/3gf2FBd

Vázquez, A. (2020-01-23). La Junta inicia el procedimiento para proteger el edificio de Lamela en La Malagueta. La Opinión de Málaga. https://bit. ly/2E0BnS1

Fecha de envío: 2020/0I/3I; Fecha de aceptación: 2020/08/2I;

Fecha de publicación: 2020/09/01 